\title{
Effect of dietary vitamin $C$ on compression injury of the spinal cord in a rat mutant unable to synthesize ascorbic acid and its correlation with that of vitamin $E$
}

\author{
D Katoh ${ }^{1}$, T Ikata ${ }^{1}$, S Katoh ${ }^{1}$, Y Hamada ${ }^{1}$ and K Fukuzawa ${ }^{2}$ \\ ${ }^{1}$ Department of Orthopedic Surgery, School of Medicine, and ${ }^{2}$ Department of Health Chemistry, Faculty of \\ Pharmaceutical Science, The University of Tokushima, 3-18-15, Kuramoto-cho, Tokushima 770, Japan
}

\begin{abstract}
The roles of vitamin $\mathrm{C}$ on secondary pathological changes after spinal cord injury were investigated by evaluating the effects of dietary vitamin $\mathrm{C}$ on experimental spinal cord injury in a mutant strain of Wistar rats unable to synthesize ascorbic acid (ODS rats). Two groups of ODS rats were given vitamin C-deficient or vitamin C-supplemented diet for 1 week before injury. Motor disturbance induced by spinal cord injury was found to be greater in the vitamin C-deficient group. Histologically, the area of bleeding in the spinal cord was also greater in the vitamin $\mathrm{C}$-deficient group. The levels of ascorbic acid and $\alpha$-tocopherol in the spinal cord tissue and serum decreased during and after compression injury of the spinal cord. The decrease of $\alpha$-tocopherol was similar in the two groups. However, the decrease of ascorbic acid was greater in the vitamin C-supplemented group. These results indicated that their protective effects against spinal cord injury are through scavenging water-soluble free radicals by vitamin $\mathrm{C}$ and lipid-soluble by vitamin $\mathrm{E}$, and the effects of these vitamins were suggested to be independent.
\end{abstract}

Keywords: spinal cord injury; rat; vitamin C; vitamin E; lipid peroxidation

\section{Introduction}

Ischemia and subsequent reperfusion injury of various tissues, including the brain, heart and uteroplacental system, are thought to be due to reactions of active oxygens. $^{1-4}$ In the central nervous system, lipid peroxidation also has been believed to contribute secondary pathological mechanism after spinal cord injury. ${ }^{5-9}$ The potential sources of oxygen radicals within the injured nervous system include the arachidonic acid cascade, catecholamine oxidation, mitochondrial leak, oxidation of extravasated hemoglobin, and later-infiltration of neutrophils.,10,11 Free irons released from hemoglobin, transferrin and ferritin may also act as catalyzing the radical-initiated peroxidation of neuronal, glial and vascular cell membranes and myelin. ${ }^{9}$ Protective effect of vitamin E on the spinal cord from pathophysiological changes after compression injury through inhibition of the subsequent increase of lipid peroxidation have been reported. ${ }^{8,12-14}$ We have also reported that vitamin $\mathrm{E}$ deficiency enhances tissue injury and increases lipid peroxidation. ${ }^{13,14}$ Decrease of the ascorbic acid level in the injured spinal cord was reported and ascorbyl free radicals are regarded as reliable indicator of freeradical mediated myocardial ischemia and post-

Correspondence: Takaaki Ikata, MD ischemic injury. ${ }^{15,16}$ Synergistic protective effects of vitamins $\mathrm{C}$ and $\mathrm{E}$ were reported against lipid peroxidation in a model membrane system ${ }^{17}$ and in solution, ${ }^{18} 20$ and against oxidation of low density lipoprotein. $^{21}$ In the present study, we investigated the effect of vitamin $\mathrm{C}$ on experimental compression injury to the spinal cord in rat by using a mutant strain of Wistar rats unable to synthesize ascorbic acid.

\section{Materials and methods}

In the present study, we used male osteogenetic disorder Shionogi (ODS) rats (150-180 g, 8 weeksold, Japan Clear Co. Ltd.), which were a developed mutant strain of Wistar rats unable to synthesize ascorbate and requires dietary supplement of ascorbate. $^{22,23}$ The animals were fed commercial chow containing $91 \mathrm{IU}$ of $\alpha$-tocopherol $/ \mathrm{kg}$ and $55 \mathrm{mg}$ of ascorbate $/ \mathrm{kg}$ and water containing $2.5 \mathrm{~g}$ of ascorbate/ litre for 7 weeks. Thereafter, the animals were given vitamin C-deficient chow containing 410 IU of $\alpha$ tocopherol $/ \mathrm{kg}$, and were divided into two groups. The control group of rats drank water containing $2.5 \mathrm{~g}$ of ascorbate/litre, and vitamin C-deficient group drank water without containing ascorbate for a week. Those animals at 16 weeks weighing 280-300 g were used for experiments. 
The animals were anesthetized by an intraperitoneal injection of sodium pentobarbital $(2.1 \mathrm{mg} / 100 \mathrm{~g}$ body weight). Laminectomies were carried out at the levels of Th12 and an extradural compression injury (a 20 grams weight placed for $5 \mathrm{~min}$ ) was induced at the Th12 as previously described. ${ }^{14}$

Motor function of the hind limbs was assessed 1 day after injury using Tarlov's criteria as follows: 0 , no voluntary movement; 1, perceptible movement; 2, good movement at joints but inability to stand; 3, ability to stand and walk; 4 , complete recovery. ${ }^{20}$

The contents in the spinal cord and in the serum of $\alpha$-tocopherol and ascorbic acid were measured. To measure those in the spinal cord, approximately $1 \mathrm{~cm}$ of the Th12 region was removed atraumatically, and frozen immediately. $\alpha$-tocopherol was extracted with ethanol-hexane $(2: 5)$ from sera and homogenates of the spinal cord, separated by HPLC on a YMCPACKA-600-3 column in a Hitachi 655A11 apparatus and measured in a Hitachi-1100 fluorescence spectrometer. ${ }^{25}$ Ascorbic acid in the spinal cord tissue and in the serum were measured colorimetorically with $\alpha, \alpha^{\prime}$ dipyridyl by the method of Murata et al. ${ }^{26}$ In this method, the reduction of $\mathrm{Fe}^{2+}$ to $\mathrm{Fe}^{+}$by vitamin $\mathrm{C}$ is measured as formation of the $\mathrm{Fe}^{2+}$-dipyridyl complex.

Lipid peroxides in the spinal cord tissues were measured by the method of Ohkawa et $a .^{27}$ and expressed as thiobarbituric acid-reactive substances (TBARS) in nmol of malondialdehyde (MDA). For the assay, a $10 \%(\mathrm{~W} / \mathrm{V})$ tissue homogenate was mixed with sodium dodecyl sulfate in acetate buffer $(\mathrm{pH} 3.5)$ and an aqueous solution of thiobarbituric acid and heated at $95^{\circ} \mathrm{C}$ for $60 \mathrm{~min}$. Then the mixture was cooled, the pink pigment was extracted with $n$ butanol-pyridine mixture and its absorbance at $532 \mathrm{~nm}$ was measured. Tetra-methoxy-propane was used as an external standard, and the levels of lipid peroxides were expressed as nmol equivalents of MDA. Serum values of those substances were also measured using same methods. These values in the spinal cord as well as in the serum were measured before, and $0,30,60$ and $120 \mathrm{~min}$ after injury $(n=6$ in each).

The injured spinal cord was examined histologically $24 \mathrm{~h}$ after compression. Tissues were stained with hematoxylin-eosin. The degree of spinal cord injury was recorded as the bleeding index $(\%)$ in coronal section (area of bleeding/area of spinal cord $\times 100$ ). This index was calculated by computed analysis of the photographs of histological preparations with an image processing system CB-TASPER (Nachet Co., France).

\section{Results}

There was no significant difference in the body weights between vitamin C-supplemented (control) and vitamin C-deficient (VCD) groups at the time of the experiments. In the control group, the ascorbic acid levels were $112.98 \pm 10.94 \mu \mathrm{g} / \mathrm{g}$ wet weight in the spinal cord and $10.33 \pm 0.99 \mu \mathrm{g} / \mathrm{ml}$ in the serum. Those levels were significantly higher $(P<0.01)$ than those of the VCD group in the spinal cord $(59.92 \pm 2.75 \mu \mathrm{g} / \mathrm{g}$ wet weight $)$ and in the serum $(4.07 \pm 0.37 \mu \mathrm{g} / \mathrm{ml})$. However, the levels of $\alpha$-tocopherol in the spinal cord and in the serum of the two groups were similar (Table 1).

Motor function of the hind limbs $24 \mathrm{~h}$ after injury was significantly poorer in the VCD group than in the control group $(n=26$ in each group, $P<0.016$, MannWhitney's U-test; Figure 1).

The ascorbic levels in the control group $2 \mathrm{~h}$ after injury were $56.89 \pm 3.93 \mu \mathrm{g} /$ in the spinal cord and $6.82 \pm 0.71 \mu \mathrm{g}$ in the serum. Those in the VCD group were $38.98 \pm 3.79 \mu \mathrm{g}$ in the spinal cord and $2.90 \pm 0.35 \mu \mathrm{g}$ in the serum (Figure 2a and b). The decrease was greater in the control group. $\alpha$ tocopherol also decreased in the spinal cord as well

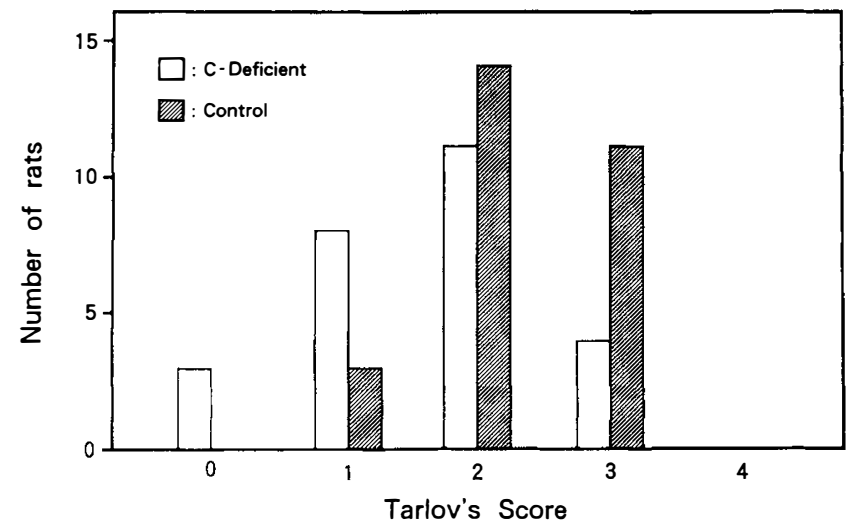

Figure 1 Motor function of rats $24 \mathrm{~h}$ after spinal cord compression with a $20 \mathrm{~g}$ weight for $5 \mathrm{~min}$ in the control and vitamin $\mathrm{C}$-deficient animals

Table 1 Levels of ascorbic acid and $\alpha$-tocopherol in the serum and spinal cord tissue

\begin{tabular}{|c|c|c|c|c|}
\hline & \multicolumn{2}{|c|}{ Ascorbic acid } & \multicolumn{2}{|c|}{$\alpha$-tocopherol } \\
\hline & $\operatorname{Serum}(\mu g / m l)$ & Spinal cord $(\mu g / g)$ & $\operatorname{Serum}(\mu \mathrm{g} / \mathrm{ml})$ & Spinal cord $(\mu \mathrm{g} / \mathrm{g})$ \\
\hline Control & $10.33 \pm 0.99$ & $112.98 \pm 10.94$ & $13.34 \pm 0.52$ & $12.75 \pm 0.68$ \\
\hline Vitamin C-deficient & $4.07 \pm 0.37^{*}$ & $59.92 \pm 2.75^{*}$ & $13.70 \pm 0.40$ & $12.91 \pm 0.80$ \\
\hline
\end{tabular}



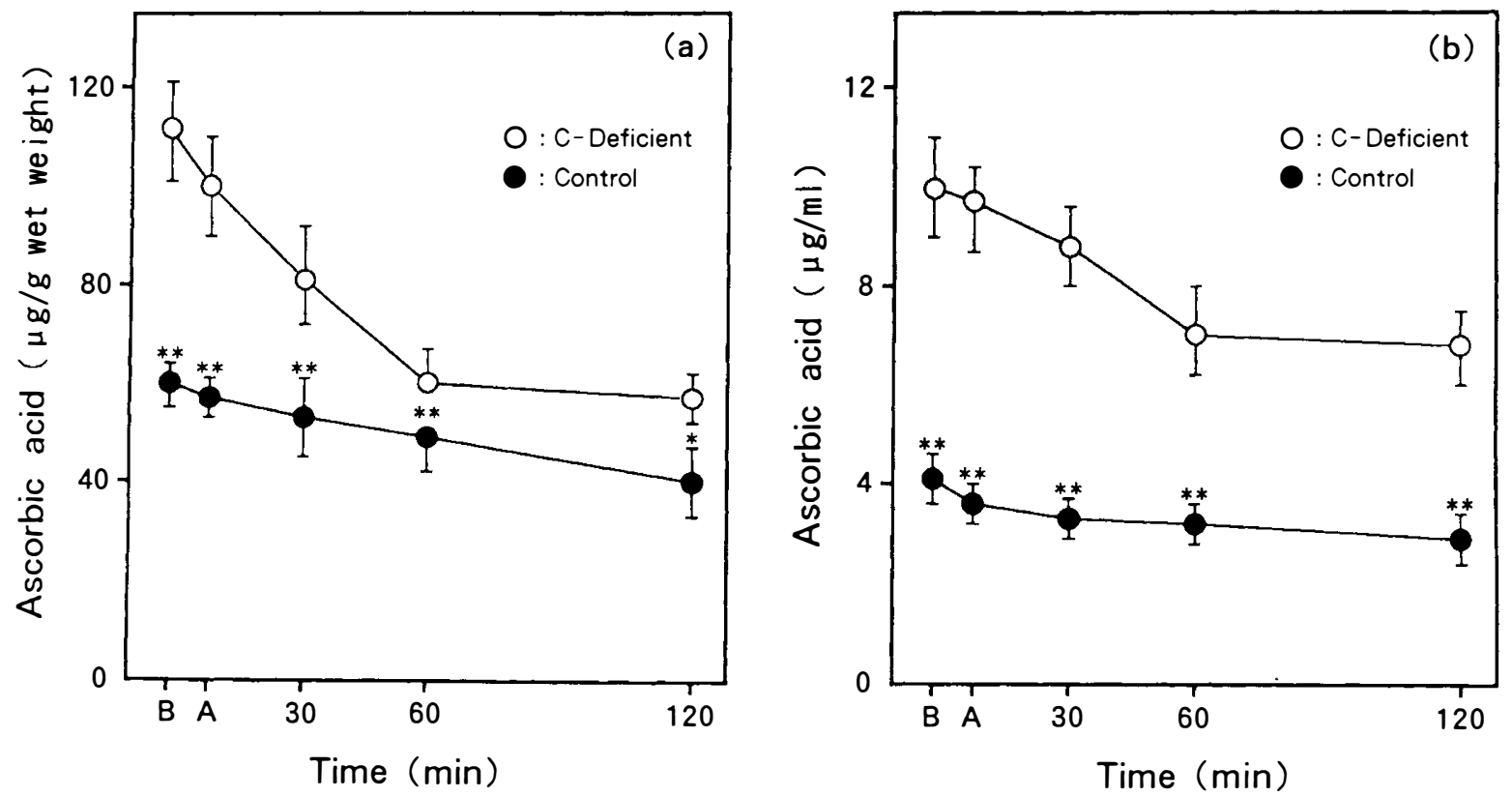

Figure 2 Changes of ascorbic acid levels in the spinal cord tissue (a) and in the serum (b) after compression injury with a $20 \mathrm{~g}$ weight for $5 \mathrm{~min}$. Points and bars represent mean and standard deviation for six animals. Significant difference from the corresponding values for the control groups $\left({ }^{*} P<0.05,{ }^{* *} P<0.01\right)$
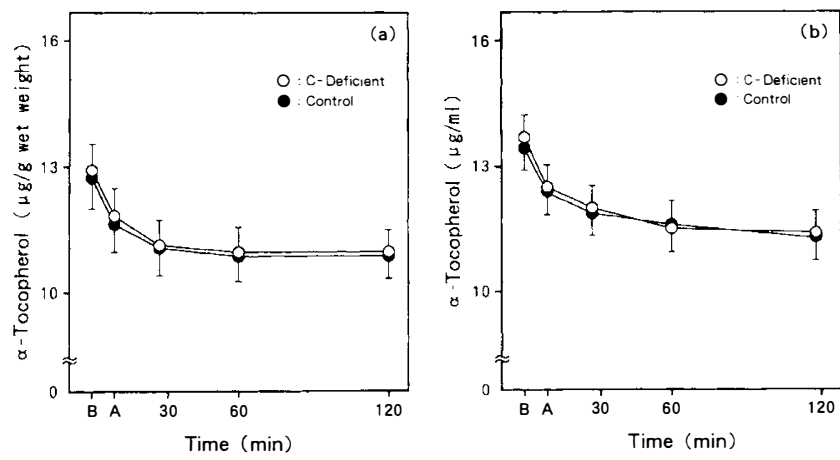

Figure 3 Changes of $\alpha$-tocopherol levels in the spinal cord (a) and in the serum (b) after compression injury with a $20 \mathrm{~g}$ weight for $5 \mathrm{~min}$. Points and bars represent mean and standard deviation for six animals

as in the serum after compression injury (Figure $3 \mathrm{a}$ and $b$ ). However, the decreases in both groups were not different significantly.

During the compression, the TBARS value increased to $139.0 \pm 4.45 \mathrm{nmol}$ wet weight in VCD group, and $117.09 \pm 4.48 \mathrm{nmol} / 100 \mathrm{~g}$ wet weight in the control group. The values in both groups increased after removal of the weights and then decreases gradualiy, and the values in the VCD groups were consistently higher than those in the control group (Figure 4).

Histological examination demonstrated a small area of hemorrhage in the grey matter and moderate

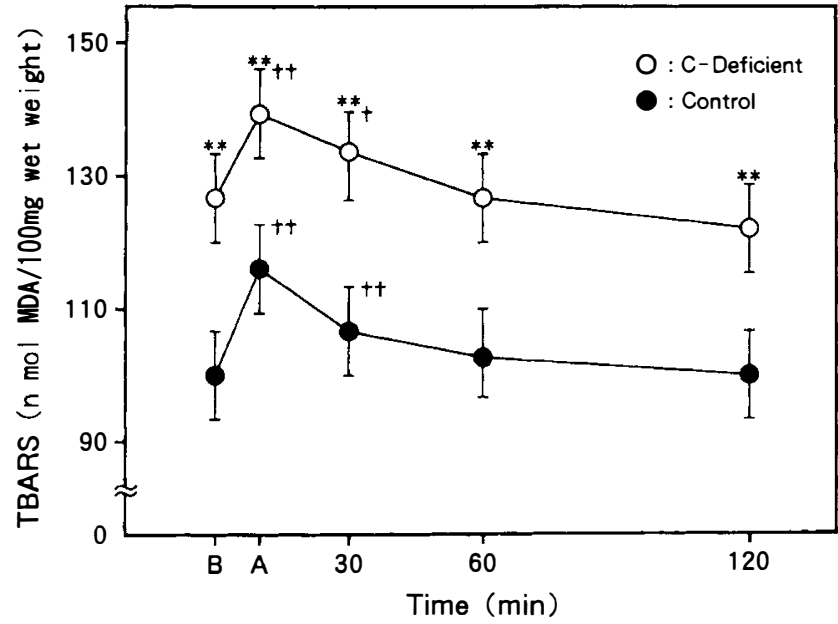

Figure 4 Changes of TBARS levels in the spinal cord and in the serum after compression injury with a $20 \mathrm{~g}$ weight for 5 min. Points and bars represent mean and standard deviation for six animals

oedema in the dorsal funiculus in the control group (Figure 5). In the VCD groups, multiple large area of hemorrhage and marked oedema were observed. The extent of the hemorrhage in the spinal cord $24 \mathrm{~h}$ after injury was significantly greater $(n=8$ in each group, $P<0.01$, unpaired $t$ test) in the VCD group $(6.72 \pm 2.02 \%)$ than in the control group $(1.80 \pm 1.04 \%)$. 

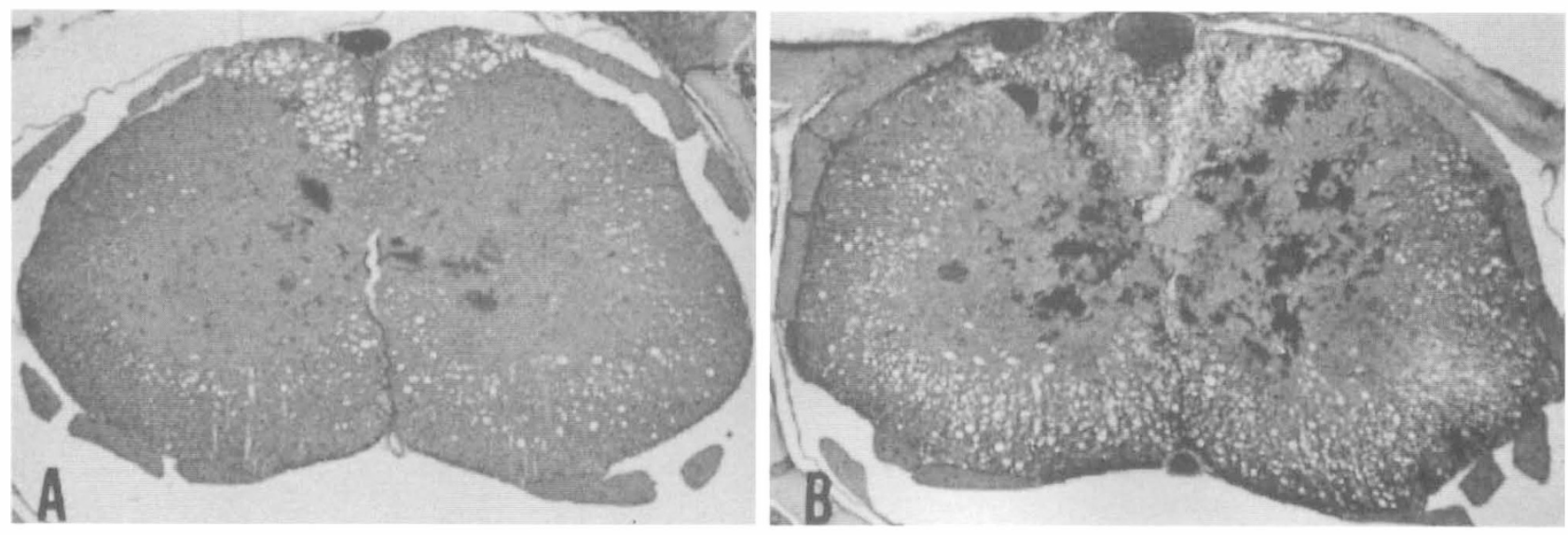

Figure 5 Hematoxylin-eosin coronal sections of the spinal cord $24 \mathrm{~h}$ after compression injuries in the control animal (A) and vitamin-C deficient animal (B)

\section{Discussion}

Vitamins $\mathrm{C}$ and $\mathrm{E}$ as well as ubiquinol (reduced coenzyme Q) are endogenous anti-oxidants, and are reported to play certain roles in the secondary injury response to the direct initial spinal cord injury. ${ }^{28,29}$ Our series of investigation on minimising the secondary cord injury have demonstrated the protective effects of dietary vitamin $\mathrm{E}$ as an anti-oxidant in the experimental spinal cord injury. ${ }^{13,14}$ The present study investigated the roles of this vitamin C, a naturally existing water-soluble antioxidant, on experimental compression injury of the spinal cord.

The antioxidative function of vitamin $\mathrm{C}$ and its effect on reducing ischemia after experimental compression injury were reported..$^{29,30}$ A pretreatment of spinal cord injured animals with a single dose of vitamin $\mathrm{C}$ has been reported to support spinal cord blood flow, although not as effectively as vitamin $\mathrm{E}$ pretreatment. ${ }^{30}$ However, pharmacological interruption of free-radical reaction of vitamin $\mathrm{C}$ has not yet been clearly demonstrated. The present result using ODS rats evaluated the functional outcome of hind limb movement, and showed that vitamin C-deficiency curtailed the recovery of its motor dysfunction. The effect was confirmed by histological evaluation of the amount of bleeding in the spinal cord. The TBARS level was also high in the spinal cord of vitamin Cdeficient animals. Although the increased amount of bleeding in the spinal cord of ODS rats might be affected by the diet without ascorbic acid for a week, these rats were fed ascorbic acid rich diet for 7 weeks from birth enable them to form collagen properly and stock it in their bodies. Therefore, these results suggested that the functional effect of vitamin $\mathrm{C}$ on ODS rats is derived from its antioxidant effect.

Ascorbic acid is not synthesized in the central nervous system. Under normal condition, its levels are closely regulated, and is conserved with a turnover rate of $2 \% \mathrm{~h}^{31,32}$ In the central nervous system injury, it is reported that the decrease of ascorbic acid does not reflect the degree of the injury. Vitamin $\mathrm{C}$ may be unable to trap peroxyl radicals in the lipid phase, but it is able to regenerate vitamin $E$ from the $\alpha$ tocopheroxyl radical, ${ }^{18,19,33}$ which suggested that the antioxidative function of ascorbic acid is synergistically correlated with $\alpha$-tocopherol. ${ }^{29}$ The present study demonstrated that ascorbic acid decreased significantly after compression injury under vitamin C-rich condition, though the decrease of $\alpha$-tocopherol was small (Figures 1 and 2). These results were consistent with the earlier reports. ${ }^{29,34}$ However, the decreases of $\alpha$ tocopherol levels of both groups were similar, although the decrease of ascorbic acid was significantly different between two groups. If ascorbic acid is consumed in order to recycle vitamine $\mathrm{E}$, the present results indicate that such an effect of vitamin $\mathrm{C}$ would be small unable to affect the level of $\alpha$-tocopherol, or the decrease of $\alpha$-tocopherol in the control group should be smaller than that of the vitamin $\mathrm{C}$-deficient group. The effect of dietary vitamin $\mathrm{C}$ was proved by the analysis of motor function, and the decrease of $\alpha$ tocopherol was similar in both groups. Thus, the antioxidant effect of ascorbic acid after spinal cord injury may be independent from that of $\alpha$-tocopherol and may act on hydrophilic condition. ${ }^{35}$ Involvement of the other scavengers including glutathione should be considered in this complexity of these processes and remains to be elucidated. ${ }^{36}$

\section{Acknowledgements}

This work was supported in part by Grants in Aid for Scientific Research from the Ministry of Education, Science and Culture of Japan. 
18 Packer JE, Slater TF, Wilson RL. Direct observation of a free radical interaction between vitamin $\mathrm{E}$ and vitamin $\mathrm{C}$. Nature 1979; 278: $737-738$.

19 Niki E, Saito T, Kawakami A, Kamiya Y. Inhibition of oxidation of methyl linolate in solution by vitamin $\mathrm{E}$ and vitamin C. $J$ Biol Chem 1984; 259: $4177-4182$.

20 Mukai K. Stop-flow investigation of the reaction between vitamin $\mathrm{E}$ radicals and vitamin $\mathrm{C}$ in solution. Biochem Biophys Acta 1987; 991: $276-279$.

21 Sato K, Niki E, Shimasaki $H$. Free radical-mediated chain oxidation of low density lipoprotein and its synergistic inhibition by vitamin E and vitamin C. Acta Biochem Biophys 1990; 279: $402-405$.

22 Mizushima Y, Harauchi T, Yoshizaki T, Makino S. A rat mutant unable to synthesize vitamin C. Experimentia 1984; 40: 359 - 361 .

23 Horio $\mathrm{F}$, et al. Ascorbic acid requirement in a rat mutant unable to synthesize ascorbic acid. J Nutr 1985; 115: $1630-1640$.

24 Tarlov IM, Klinger H. Spinal cord compression studies. II. Time limits for recovery after acute compression in dogs. Arch Neurol Psychiat 1954; 71: 271 - 290.

25 Taylor SL, Lamden MP, Tappel AL. Sensitive fluorometric method for tissue $\alpha$-tocopherol analysis. Lipids 1976; 11: $530-$ 538.

26 Murata A, et al. Determination of vitamin C by $\alpha, \alpha^{\prime}$-dipyridyl method (in Japanese). Bull Fac Agr Saga Univ 1986; 61: 919.

27 Ohkawa H, Ohishi N, Yagi K. Assay of lipid peroxides in animal tissues by thiobarbituric acid reaction. Analyt Biochem 1979; 95: $351-358$.

28 Flamm ES, et al. Free radicals in cerebral ischemia. Stroke 1978; 9: $445-447$.

29 Lemke M, Frei B, Ames BN, Faden AI. Decrease in tissue levels of ubiquinol- 9 and -10 , ascorbate and $\alpha$-tocopherol following spinal cord impact trauma in rats. Neurosci Lett 1990; 108: 201 206.

30 Hall ED, Braughler JM. Role of lipid peroxidation in posttraumatic spinal cord degeneration: a review. Central Nerv Syst Trauma 1987; 3: $281-293$.

31 Chatterjee IB, Majumder AK, Nandi BK, Subramian N. Synthesis and some major functions of vitamin $\mathrm{C}$ in animals. Ann NY Acad Sci 1975; 258: $24-47$.

32 Spector R, Spector AZ, Snodgrass S. Model for transport in the central nervous system. Am J Physiol 1977; 232: 73 - 79.

33 Tappel AL. Will antioxidant nutrients slow aging process? Geriatrics 1968; 23: 97 -- 105.

34 Yue T-L, Barone FC, Gu J-L, Feuerstein GZ. Brain $\alpha$-tocopherol levels were not altered following ischemia/reperfusion-induced cerebral injury in rats and gerbils. Brain Res 1993; 610: $53-56$.

35 Burton GW, et al. Biokinetics of dietary RRR- $\alpha$-tocopherol in the male guinea pig at three levels of vitamin $C$ and two levels of vitamin E. Evidence that vitamin C does not 'spare' vitamin $\mathrm{E}$ in vivo. Lipids 1990; 25: $199-210$.

36 Lyrer $\mathrm{P}$, et al. Levels of low molecular weight scavengers in the rat brain during focal ischemia. Brain Res 1991; 567: 317 -.. 320 . 